\title{
AVALIAÇÃO CLÍNICA E CITOLÓGICA DE CAVALOS DE TRAÇÃO, ACOMETIDOS POR DOENÇAS RESPIRATÓRIAS DAS VIAS AÉREAS INFERIORES NO PARANÁ.
}

\author{
Mariane Angélica Finger ${ }^{1}$, Selene Cirio Leite ${ }^{1}$, Lilian Pamela Tapia Carreno \\ Dornbusch ${ }^{1}$, Ivan Deconto ${ }^{1}$, Ivan Roque de Barros Filho ${ }^{1}$, Peterson Triches \\ Dornbusch ${ }^{1}$
}

\author{
1 UFPR \\ Correspondência: Mariane Angélica Finger: mari.finger.ufpr@gmail.com
}

\begin{abstract}
RESUMO: As doenças do trato respiratório posterior dos equinos são achados frequentes na prática diária da clinica e por isso é necessário o desenvolvimento de métodos diagnósticos mais rápidos e eficientes. Neste sentido ressalta-se o lavado broncoalveolar (LBA), técnica de coleta e avaliação celular do conteúdo das vias respiratórias posteriores. O objetivo deste estudo foi comparar o padrão citológico de LBA de cavalos saudáveis com animais enfermos de pequenos proprietários rurais na região de Tijucas do Sul, Paraná e também verificar as enfermidades respiratórias do trato respiratório inferior mais frequentes nestes cavalos. Foram realizados exames clínicos e o LBA em trinta cavalos, sendo vinte acometidos de pneumonia, broncopneumonia e doença inflamatória recorrente das vias aéreas (grupo enfermo) e dez animais saudáveis (grupo controle). Nas análises citológicas das amostras foram avaliadas a contagem quantitativa e qualitativa das células, a quantidade de muco nas amostras e demais achados, como a presença de colônias bacterianas, ovos de parasitas e material vegetal. No exame clínico, $95 \%$ dos animais enfermos apresentaram tosse e $80 \%$ secreção nasal. Na contagem total de células o grupo enfermo apresentou maior quantidade de células. A contagem diferencial apresentou aumento significativo de neutrófilos e eosinófilos, com redução na proporção de macrófagos. Houve destaque para a presença de colônias bacterianas em amostras de oito animais enfermos. Foram verificados, ainda, casos de verminose pulmonar, influenza e doença inflamatória das vias aéreas, sendo que em apenas dois casos os diagnósticos clínico e citológico foram inconclusivos. A técnica do LBA comprovou ser simples e rápida, permitindo aprimorar o diagnostico final das enfermidades respiratórias do trato posterior de equinos em condições de campo.
\end{abstract}

Palavras-chave: equinos; LBA; pneumonia; verminose pulmonar

\section{CLINICAL AND CYTOLOGYC EVALUATION OF TRACTION HORSES WITH RESPIRATORY DISEASES OF LOWER AIRWAYS, PARANÁ}

\begin{abstract}
Lower airway diseases diseases are common findings in equine clinics routine and so it is necessary to develop diagnostic methods faster and more efficient. In this way, the bronchoalveolar lavage (BAL) allows to collect and evaluate the lower airways contents. The goal of this paper is to establish a cytological standard of BAL in healthy horses, used for traction in field conditions and to verify lower respiratory tract diseases more common in animals of small rural properties in Tijucas do Sul region, Parana state. Clinical exams and BAL were done in thirty horses, of which twenty had pneumonia, bronchopneumonia and recurrent inflammatory airway disease, and ten were healthy. In cytological analysis were evaluated quantitative and qualitative counting, mucus quantity and other findings, like bacterial colonies, parasite eggs and vegetal material. At clinical exam, $95 \%$ of sick horses presented cough and $80 \%$ had nasal secretion, also hyperthermia and dispneia. At quantitative counting, sick horses had more cells. At differential counting, they presented a number significant higher of neutrophils and eosinophils, with a macrophages reduction. There were bacterial colonies in eight sick horses. Cases of pulmonary worms, viral infections and inflammatory airways disease was found, and clinical and cytological diagnosis was inconclusive just in two cases. BAL technique proved to be fast and simple, allowing to improve final diagnosis of lower respiratory tract diseases in horses in field conditions.
\end{abstract}

Key Words: equine; BAL; pneumonia; lung horn 


\section{INTRODUÇÃO}

Estudos demonstram que grandes prejuízos econômicos na indústria equestre são consequências de problemas locomotores, seguidos de afecções respiratórias (Moraes et al., 2009). Assim orienta-se que o diagnóstico de doenças respiratórias do trato respiratório posterior deve relacionar os dados da história clínica, do exame físico e dos exames complementares (Reed e Bayly, 1998). Dentre os exames complementares das enfermidades das vias aéreas destacase 0 lavado broncoalveolar (LBA), técnica que proporciona resultados rápidos, confiáveis e específicos.

O procedimento consiste em introduzir, de forma não traumática, solução fisiológica no interior das vias aéreas, com finalidade de coletar o lavado proveniente de brônquios, bronquíolos e alvéolos. A vantagem é sua aplicação a campo, sendo de fácil realização e de baixo custo econômico. As células encontradas no LBA são neutrófilos, macrófagos, linfócitos, eosinófilos, mastócitos e células epiteliais; deve-se levar em consideração a quantidade das células, sendo a contagem o fator classificatório para definir animais saudáveis e enfermos. Diferenças significativas para interpretação citológica entre autores podem surgir, e se devem a fatores raciais, climáticos e ambientais (Reed e Bayly, 1998). Costa e Macoris (2007) afirmaram que a técnica permite identificação de doenças das vias aéreas posteriores em estágio inicial, tornando-se um importante instrumento para diagnóstico e orientação da conduta terapêutica no paciente.

O objetivo do estudo foi comparar padrão citológico de lavado broncoalveolar de cavalos saudáveis com cavalos enfermos utilizados para tração em pequenas propriedades rurais, além de comparar a eficiência do exame físico com o lavado broncoalveolar, em animais naturalmente acometidos por doenças pulmonares na região de Tijucas do Sul, Paraná.

\section{MATERIAL E MÉTODOS}

O experimento foi realizado no município de Tijucas do Sul, Paraná, com coordenadas de $25^{\circ} 55^{\prime} 40^{\prime \prime} \mathrm{S}, 49^{\circ}$ $11^{\prime} 56^{\prime \prime} \mathrm{W}$, sendo a altitude média do município de 900 metros acima do nível do mar, nos meses de abril a outubro, quando as temperaturas variaram de 2 a $25^{\circ} \mathrm{C}$.

Foram utilizados 30 animais, de diferentes propriedades, sendo 10 animais saudáveis, constituindo o grupo controle, composto por oito fêmeas e dois machos. Os grupos foram definidos através do exame clínico. O peso médio dos animais do grupo foi de 335,3 \pm $42,3 \mathrm{~kg}$. A vermifugação foi recente, tendo sido utilizado ivermectina, da marca Equalan $\AA$, mas sem vacinas contra enfermidades respiratórias. A alimentação era baseada em capim de baixa qualidade, ração, milho em espiga, rolão de milho e feno, sendo que todos eram mantidos em piquetes.

O grupo enfermo foi composto por 20 animais, sendo 13 fêmeas e 07 machos. O peso médio dos animais do grupo foi de $342,4 \pm 60,8 \mathrm{~kg}$. A alimentação era basicamente a mesma do Grupo Controle, e apenas três possuíam vermifugação recente, sendo que nenhum foi vacinado contra enfermidades respiratórias, e de forma semelhante, todos eram mantidos em piquetes.

Após a coleta de dados do histórico do animal, foi realizado o exame físico, sendo avaliados frequência e auscultação respiratória e cardíaca; estado de hidratação; coloração de mucosas; tempo de preenchimento capilar (TPC); palpação de linfonodos; percussão torácica, 

das vias aéreas inferiores no Paraná

temperatura retal e atitude ao exame, conforme parâmetros de referência descritos por Gonçalves e Feitosa (2008). Como critérios de inclusão no grupo de animais enfermos, os equinos apresentaram sinais de alteração respiratória como tosse, dispnéia, secreção nasal ou alteração na auscultação pulmonar.

Para realização do LBA, fez-se a contenção física do animal e respectiva sedação, com cloridrato de xilazina a 10\% (Sedazine®, Fort Dodge Saúde Animal), na dose de $0,25 \mathrm{mg} / \mathrm{kg}$, por via intravenosa. Após 5 minutos, uma sonda bivona ${ }^{\circledR}$ de lavado broncoalveolar para equinos foi introduzida pelo meato ventral da narina esquerda, até a sonda parar em um brônquio. Esta sonda possui $10 \mathrm{~mm}$ de diâmetro, por isso sabe-se que no momento em que não é mais possível progredir com a mesma ela encontra-se em um brônquio. A sonda fica fixa através de um balão que é inflado pelo condutor da mesma. Foram introduzidos $100 \mathrm{ml}$ de solução fisiológica comercial, sendo então removido rapidamente por sucção, com seringa descartável de 60 $\mathrm{ml}$. Concluída a aspiração da amostra, a seringa foi desacoplada da sonda, o conteúdo homogeneizado e uma alíquota de $3 \mathrm{ml}$ separada para exame citológico quantitativo do LBA. O restante do fluído foi colocado em uma Câmara de sedimentação, tipo SUTA, por 45 minutos. $O$ botão celular formado na lâmina foi fixado e corado pela técnica de Romanovsky (Hewson e Viel, 2002).

Para análise quantitativa, 0 líquido do LBA foi homogeneizado e as células nucleadas totais contadas com 0 auxílio de câmara de Neubauer em microscópio óptico, em objetiva de 40x (Biava et al., 2006).

Para análise diferencial contou-se o total de 400 células, diferenciando as proporções de células epiteliais, neutrófilos, linfócitos, eosinófilos e macrófagos; levou-se em consideração a presença de outros achados, como ovos e larvas de parasitas, bactérias, hifas de fungos e artefatos, como poeira e fragmentos vegetais. Também foram observadas a presença e quantidade de muco na amostra, sendo classificadas as lâminas em graus: 0 - ausente, 1 pouco muco, 2 - muco moderado e 3 muco em excesso.

A análise estatística dos dados numéricos obtidos foi realizada por meio do teste T para amostras não pareadas e para os dados de escore visual utilizou-se o teste de Mann-Whitney, com nível de significância de 5\% $(p<0,05)$. Todos os cálculos foram realizados com o programa GraphPad Prism v.5, San Diego - Califórnia, EUA.

\section{RESULTADOS}

A evolução dos sinais apresentou-se com 3,2 $\pm 3,6$ semanas, estando listados na Tabela 1.

No grupo enfermo a frequência respiratória $(\mathrm{FR})$ foi de $35,2 \pm 17,7$ movimentos/minuto; frequência cardíaca (FC) de 43,8 $\pm 6,6$ batimentos/minuto. A percussão torácica não se mostrou alterada em nenhum dos animais. No grupo controle a FR foi de $32,12 \pm 12,3$ movimentos/minuto e a FC $35,2 \pm 10,1$ batimentos/minuto. Não houve diferença significativa entre os grupos.

\begin{tabular}{lcc}
$\begin{array}{l}\text { Tabela 1: Resumo dos principais achados no exame clínico dos animais enfermos. } \\
\text { Sinais Clínicos }\end{array}$ & $\begin{array}{l}\text { Valores } \\
\text { absolutos }\end{array}$ \\
& 19 & Valores relativos \\
\hline Tosse & 16 & $95 \%$ \\
Secreção nasal & 05 & $80 \%$ \\
Secreção Nasal Serosa & 05 & $25 \%$ \\
Secreção Nasal Mucopupurulenta & 06 & $25 \%$ \\
Secreção Nasal Purulenta & 10 & $30 \%$ \\
Reflexo de tosse & 05 & $50 \%$ \\
Aumento dos Linfonodos submandibulares & 05 & $25 \%$ \\
Hipertermia & 08 & $25 \%$ \\
Dispnéia & 05 & $40 \%$ \\
Crepitação Pulmonar & 01 & $25 \%$ \\
Sibilos & 05 & $05 \%$ \\
Secreção na auscultação traqueal & & $25 \%$
\end{tabular}


A contagem de células $/ \mu \mathrm{L}$ demonstrou maior quantidade das mesmas no Grupo Enfermo (500-1000 células por $\mu \mathrm{L}$ ), contrastando com a celularidade do Grupo Controle (até 500 células por $\mu \mathrm{L}$ ), conforme mostra a Figura 1.

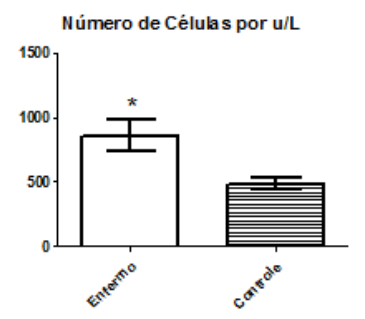

Figura 1: Lavado Broncoalveolar de Eqüinos. Contagem total de células/ $/ \mu l$ no Grupo Enfermo e no Grupo Controle, onde * $p<0,05$.

A Figura 2 mostra o escore da presença de muco nas amostras obtidas de animais saudáveis e enfermos, onde houve diferença significativa entre os grupos $(\mathrm{P}=0,04)$.

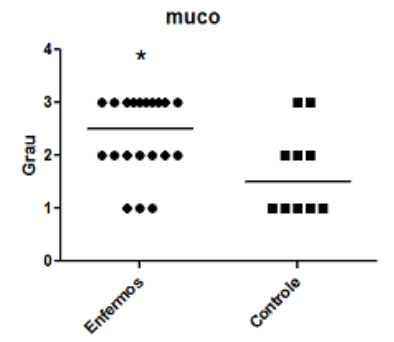

Figura 2: Lavado Broncoalveolar de Eqüinos. Escore da presença de muco observada no Grupo Enfermo e no Grupo Controle, a linha representa a mediana, onde * $p<0,05$.

Nas análises qualitativas das amostras, pode-se observar nas contagens diferenciais das células que as proporções de linfócitos, células epiteliais e mastócitos encontrada nas amostras de LBA, não diferiram significativamente e estão demonstradas na Figura 3. As quantidades de neutrófilos, macrófagos e eosinófilos foram significativas e estão demonstradas na Figura 4.

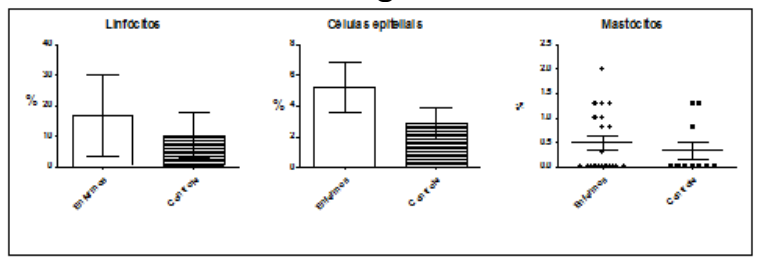

Figura 3. Lavado Broncoalveolar de Eqüinos. Porcentagem de linfócitos, células epiteliais e mastócitos observada no Grupo Enfermo e no Grupo Controle onde $p<0,05$.

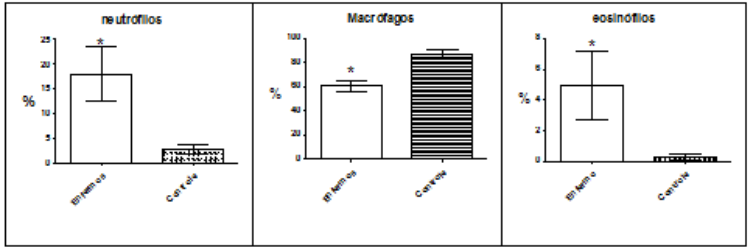

Figura 4. Lavado Broncoalveolar de Eqüinos. Porcentagem de neutrófilos, macrófagos e eosinófilos no Grupo Enfermo e no Grupo Controle onde * $p<0,05$.

Além da contagem celular nas amostras, foram observadas as presenças de outros achados citológicos, conforme especificado na Tabela 2. Vale ressaltar que a maior parte das amostras onde se detectou presença de bactérias, foi possível identificar, também, células da orofaringe. Sendo que em uma das amostras foi possível identificar uma forma adulta de Dictyocaulus Arnfield, com ovos larvados em seu interior, Figura 5.

Tabela 2. Representação de outros achados citológicos nas amostras de LBA do Grupo Enfermo e do Grupo Controle.

\begin{tabular}{lll}
\hline \multicolumn{1}{c}{ Achado } & Enfermos $(\mathrm{n}=20)$ & Controle $(\mathrm{n}=10)$ \\
\hline Fragmentos vegetais & $7(35 \%)$ & $3(30 \%)$ \\
Bactérias & $8(40 \%)$ & $2(20 \%)$ \\
Hifas & $5(25 \%)$ & $3(30 \%)$ \\
Ovos de dictiocallus & $3(15 \%)$ & 0 \\
\hline
\end{tabular}

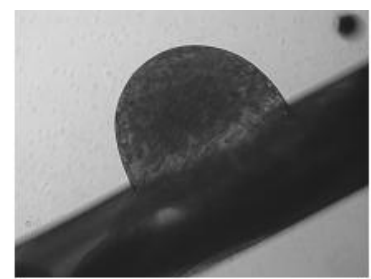

Figura 5. Fêmea adulta de Dictyocaulus Arnfieldi, com ovos larvados em seu interior.

Os dados do histórico, exame físico e análise citológica do LBA, foram correlacionados e pôde-se obter 0 diagnóstico das enfermidades do trato respiratório inferior, demonstrado na Figura 6.

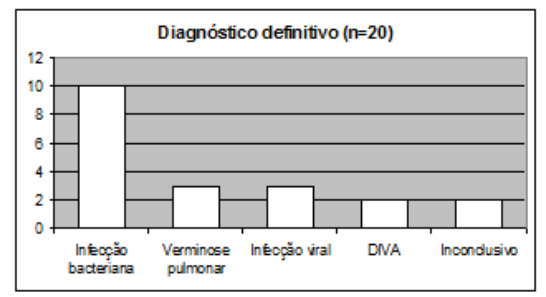

Figura 6. Representação de diagnóstico definitivo para as amostras de LBA coletadas do $\mathrm{Grupo}$ Enfermo. (DIVA= Doença inflamatória vias aéreas) 


\section{DISCUSSÃO}

O procedimento do LBA não é padronizado mundialmente e apresenta diferenças na execução da técnica, o que muitas vezes dificulta a repetibilidade dos resultados. No presente estudo, foi realizada a inoculação de $100 \mathrm{ml}$ de solução fisiológica comercial, o mesmo procedimento anteriormente adotado por Biava et al. (2006) em seu trabalho com cavalos Quarto-de-Milha na região de Curitiba. Mansmann e King (2008) sugerem que o volume infundido para realização do LBA influencia na contagem celular diferencial e que para ser realizado efetivamente seriam necessárias quantidades maiores que $250 \mathrm{ml}$ de líquido. Porém, os mesmos autores afirmaram que se não houver variação no volume infundido em todos os animais, o resultado é confiável da mesma forma. Portanto faz-se necessária a padronização da técnica de cada laboratório, devendo haver o critério de infundir sempre um mesmo volume. Devido a grande interferência de fatores climáticos nos resultados do LBA, como pode ser observado em outras regiões com climas que variam de regiões áridas a climas extremamente frios, é importante estabelecer valores de referência em animais normais e doentes nas diferentes regiões de atuação dos clínicos veterinários de forma a fornecer subsídios aos colegas.

No exame físico os movimentos respiratórios e os batimentos cardíacos por minuto dos animais doentes não diferiram da média do grupo controle, apesar da presença de alterações no LBA. Fortes Júnior (2005) afirmou que a presença de tosse pode ocorrer em qualquer indivíduo com as vias aéreas irritadas, e sua ausência, bem como de secreção visível externamente, não descarta a existência de exsudato nas vias aéreas, pois grande parte da secreção produzida é deglutida quando atinge a faringe.

A contagem total de células no presente experimento foi significativamente alta no Grupo Enfermo e, segundo Hewson e Viel (2002), é difícil mensurar valores de referência para 0 LBA, pois a interpretação citológica varia conforme a técnica de coleta e processamento, tipo de líquido infundido, $\mathrm{pH}$, volume infundido e recuperado, diâmetro do material de coleta e tempo de estocagem da amostra antes do processamento, além de sofrer influência por alterações climáticas e regionais. Entretanto, uma vez obtida sua padronização, o aumento na contagem total de células é um indicativo de alteração das vias aéreas inferiores. A técnica utilizada neste experimento foi a descrita por Biava et al., 2006.

O LBA é bastante útil na interpretação e formulação de diagnóstico diferencial porque a citologia pode indicar processos inflamatórios de etiologia alérgica, fúngica, bacteriana, parasitária ou por processos físicos (Biava et al.,2006). Costa e Macoris (2007) afirmaram que as células predominantes no LBA de animais saudáveis seriam macrófagos alveolares e células epiteliais, com variações relacionadas à metodologia empregada. Segundo Lessa et al. (2007) a contagem diferencial deve avaliar no mínimo 300 células, levandose em conta aspectos morfológicos e do muco. Deve predominar no LBA de animais saudáveis, macrófagos alveolares, linfócitos, número reduzido de células epiteliais ciliadas, não ciliadas e eosinófilos. Os mesmos autores também consideraram que amostras de LBA de animais sadios geralmente apresentam proporções aproximadamente iguais entre macrófagos alveolares e linfócitos, observando celularidade moderada, 
com existência discreta de muco no fundo das lâminas. Nos animais enfermos houve um aumento significativo no número de neutrófilos, macrófagos e eosinófilos com relação ao grupo controle, que apresentou proporções compatíveis com animais saudáveis de acordo com a literatura.

Segundo Carneiro (2002), a ação de bactérias e leucócitos reduz a ação da defesa mucociliar por meio do aumento da secreção de muco e diminuição da função ciliar. A maior atividade inflamatória das vias aéreas acarreta em maior quantidade de muco nas amostras de animais acometidos o que pode ser observado nos animais enfermo. Neste estudo observou-se uma maior quantidade de muco nas lâminas dos animais enfermos com diferença significativa 0 que era esperado.

A maior concentração de neutrófilos, nos animais enfermos estava associada com presença de inflamação das vias aéreas, como na pneumonia e broncopneumonia bacteriana. Foram encontrados para 0 grupo controle cerca de $5 \%$ de neutrófilos, o que está de acordo com Carneiro (2002) e Zinkl (2002). Desta forma, número elevado de neutrófilos no LBA é um indicativo de doença das vias aéreas inferiores.

A quantidade de eosinófilos, menor que $1 \%$ para o Grupo Controle e 4-6\% para o Grupo Enfermo, mostrouse discretamente aumentada nestes pela maior atividade inflamatória, especialmente ligada à presença de parasitas adultos e de ovos Dictyocaullus arnfieldi, principalmente porque a maioria dos animais doentes (17/20) não possuía histórico de desverminação recente. Em outro estudo encontramos valores similares para animais saudáveis na região metropolitana de Curitiba (Biava et al., 2006).
A redução do número de macrófagos nos animais enfermos devese ao aumento proporcional nos outros grupos celulares. Tanto Speirs (1999) quanto Fernandes et al. (2000) afirmaram que $O$ tipo celular predominante no LBA com cavalos clinicamente sadios foi o macrófago, confirmando a capacidade do LBA em obter amostras provenientes das vias aéreas mais distais.

A porcentagem de mastócitos encontrada no Grupo Enfermo foi de 0,5-0,7\%, enquanto que no Grupo Controle foi de $0,1-0,6 \%$ e não foi significativa, concordando com Zinkl (2002), que relatou que é raro encontrar mastócitos no LBA, obtendo-se proporções para animais saudáveis menores que $2 \%$. Mastócitos são encontrados com em pequenas quantidades nas amostras de LBA das vias aéreas inferiores distais e alveolares (Hughes et al., 2003).

A porcentagem de células epiteliais encontrada para 0 grupo Enfermo foi de 4-6\%, e para o Grupo Controle, 2-4\%. Este valor encontra-se dentro do normal conforme cita Biava et al. (2006) que admitem valores de 1,0 \pm $3,2 \%$. As células epiteliais têm característica de apresentar cílios e membrana cuticular, o que as identifica as mesmas no caso da perda dos cílios (Fortes Junior, 2005) e o número pode variar de acordo com o ponto de aspiração (Lessa et al., 2007). Um alto número de células epiteliais no LBA pode indicar trauma nas vias aéreas proximais (Fernandes, Mori e Saches, 2000) que pode ser induzido pela passagem da sonda ou outro fator anterior ao exame.

Substâncias externas ao trato respiratório inferior podem ser encontradas no LBA. Usualmente, são resultados de contaminação durante 0 procedimento, podendo também ser inaladas e não serem expelidas pela ação mucociliar do epitélio respiratório 

das vias aéreas inferiores no Paraná

(Zinkl, 2002). Esse é o caso da presença de fragmentos vegetais nas amostras, que podem ter sido contaminadas no momento da introdução da sonda, a qual levou consigo fragmentos que encontravamse na luz ou nas paredes da nasofaringe. A presença de hifas pode ser atribuída à contaminação acidental, tanto do material quanto das amostras, assim como a presença bacteriana nas amostras do Grupo Controle.

\section{CONCLUSÃO}

A técnica do lavado broncoalveolar é simples, econômica e de fácil realização em condições de campo, permitindo maior acurácia no diagnóstico das enfermidades respiratórias. $O$ grupo enfermo demonstrou diferenças qualitativas e quantitativas na avaliação celular do lavado broncoalveolar, quando comparado aos animais saudáveis, apesar de não terem sido encontradas diferenças significativas em outros parâmetros clínicos, o que demonstra a importância do LBA no diagnóstico de doenças respiratórias Foi possível estabelecer os valores de referência para o lavado broncoalveolar de cavalos utilizados para tração e mantidos em condições de campo na região de Tijucas do Sul.

\section{REFERÊNCIAS}

BIAVA, J. S.; GONÇALVES, R. C.; DORNBUSCH, P. T. et al. Avaliação clínica e citológica do trato respiratório de cavalos da raça Quarto de milha, após o exercício.

Archives of Veterinary Science, v.11, n.1, p.60-65, 2006.

CARNEIRO, G. F. Afecções do Sistema Respiratório relacionadas à performance do cavalo atleta. Revista do Conselho Federal de Medicina Veterinária, v.26, p.57-70, 2002.

COSTA, N. S.; MACORIS, D. G. Citologia do Lavado Broncoalveolar de Equinos da Polícia Militar do Distrito Federal. Brazilian Journal
Veterinary Research Animal Science, v.44, p.268-247, 2007.

FERNANDES, W. R.; MORI, E.; SANCHES, A. Avaliação citológica de lavados

traqueobrônquico e broncoalveolar em cavalos clinicamente sadios pelo método de coloração de Rosenfeld. Arq. Bras. de Med. Veterinária e Zootecnia, v.52, n.6, p.604-609, 2000.

FORTES JÚNIOR, W. F. Citologia pulmonar de equinos (equus caballus) em situação de manejo estrito a campo e estabulados. Mestrado em Ciências veterinárias. Curitiba(PR):UFPR, 2005.

GONÇALVES, R. C.; FEITOSA, F.L.F. Semiologia do Sistema Respiratório. In FEITOSA, F.L.F. Semiologia Veterinária, 2a․ ed.São Paulo: Roca; 2008, p.275-292.

HEWSON, J.; VIEL, L. (2002). Sampling, microbiology and cytology of respiratory tract. Disponível em: www.ivis.org/special_books/ lekeux/viel/ivis.pdf . Acesso em 01/08/2010.

HUGHES, K. J.; MALIKIDES, N.; HODGSON, D. R. et al. Comparison of tracheal aspirates and bronchoalveolar lavage in racehorses .1 . Evaluation of cytological stains and the percentage of mast cells and eosinophils. Equine Veterinary Journal, v.35, n.3, p.264268, 2003.

LESSA, D. A. B.; MORI, E.; VIANA, E. B. et al. Lavado Broncoalveolar em Equinos: Revisão de Literatura Parte 2: Achados Citológicos.

Arquivo de Ciências Veterinárias e Zoologia, v.10, n.1, p.31-38, 2007.

MANSMANN, R. A.; KING, C. How to perform Bronchoalveolar Lavage in practice.

Proceedings of the Annual Convention of the AAEP, v.44, p.186-88,1998.Disponível em: www.ivis.org/proceedings/aaep/1998/mansmann .pdf .Acesso em: 01/08/2010.

MORAES, C. M.; VARGAS, A. P. C.; LEITE, F. P. L. et al. Adenite equina: sua etiologia, diagnóstico e controle. Ciência Rural. v.39, n.6, 2009.

REED, S. M.; BAYLY, W. M. Equine Internal Medicine. 1 ed. Philadelphia (WB). Saunders Company, 1998.

SPEIRS , V.C. Exame Clínico de Equinos. 1 ed. Porto Alegre: Artmed, 1999.

ZINKL, J. G. Lower Respiratory Tract. In:Cowell, R. L.; Tyler, R. D. Cytology and Hematology of the Horse. St Louis (Missouri): Mosby.2002, p.73-86 